\title{
Silicon-Basing Ceramizable Composites Containing Long Fibers
}

\author{
Zbigniew Pędzich ${ }^{1}$, Rafał Anyszka², Dariusz M. Bieliński ${ }^{2}$, Magdalena Ziąbka ${ }^{1}$, \\ Radosław Lach ${ }^{1}$, Magdalena Zarzecka-Napierala ${ }^{1}$ \\ ${ }^{1}$ Department of Ceramics and Refractory Materials, AGH-University of Science \& Technology, Krakow, Poland \\ ${ }^{2}$ Institute of Polymer and Dye Technology, Lodz University of Technology, Lodz, Poland \\ Email: pedzich@agh.edu.pl
}

Received July 2013

\begin{abstract}
Ceramization is a phenomenon which assures compactness of polymer-based composites in the case of their thermal degradation caused by open fire or exposure at high temperatures. This phenomenon is based on preventing volatiles of thermal decomposition of silicone rubber from evacuation by creation of ceramic layer. This ceramized structure is composed of mineral filer particles, connected by fluxing agent-glassy phase. The ceramic barrier created during firing is aimed to protect copper wire inside the cable from melting, being additionally strong enough to maintain integrity of electrical circuit. The paper presents experimental data on mechanical properties of silicone rubber composites strengthened additionally with long fibers of different types - aluminosilicate and polyamide (Kevlar) ones. Fibers were introduced into composites in oriented way. Mechanical properties were investigated taking into account fiber orientation anisotropy. Ceramization process of composites was described by observation of morphology and strengthen measurements of samples fired at $1000^{\circ} \mathrm{C}$.
\end{abstract}

Keywords: Silicone Rubber; Ceramization; Composites; Polyamide Fibers; Aluminosilicate Fibers

\section{Introduction}

Silicone-basing ceramizable composites are very high loaded systems, of filler content at the level of 100 - 120 phr (part per hundred of rubber). The characteristic of the filler particles and their interaction with silicone matrix decides the mechanical properties of the composites and it is important from the point of view of mix preparation and its further processing by extrusion.

The type, the volume, the grain size distribution of these additives are decisive for shaping of microstructure of ceramized body [1-8]. Moreover, ceramization condition can strongly influence its final microstructure and other properties [9-11].

Three major processes occurring during fire and supporting ceramization can be featured: 1) sintering of mineral filler particles due to hydroxyl groups condensation which are presented on its surface, what leads to obtaining larger ceramic domains. 2) creation of silica bridges between mineral particles as a result of thermal decomposition of silicone rubber matrix in presence of oxygen and mineral powders which surfaces can act as a catalyzer of silica creation. 3) incorporation of a low softening point temperature glassy frit (fluxing agent) which particles melt in elevated temperature and create connec- tions between mineral filler particles [12-18].

Continuous and porous structure which can be obtained protects covered elements (for example copper wires) against thermal and mechanical external stresses and can maintain functioning of important devices (sprinklers, lifts, etc.) even up to three hours under fire conditions (even when temperature approaches cooper melting point) [19-23].

Presented paper concerns the possibility of using long fibers as the reinforcing agent. These fibers added simultaneously with other fillers could improve mechanical properties of composites in vulcanized state and also they could influence properties of composite bodies after ceramization. The possible application of investigated materials is cable industry. The only effective method of cable manufacturing is extrusion process. Such method could be utilized to easy orientation of long fibers parallel to extrusion direction and consequently to fabrication of composites with strong anisotropy of mechanical properties.

\section{Experimental}

Investigated materials were composites prepared on the base of silicone rubber containing $40 \mathrm{phr}$ (part per hun- 
dred of rubber) reinforcing, fumed silica. These premixes were produced by Silicony Polskie Nowa Sarzyna (Poland). The reference material was composed of $40 \mathrm{phr}$ of wollastonite TERMIN 283 originated from Qarzwerke (Germany) and also $20 \mathrm{phr}$ of fluxing agent-glass frit FR2050 (commercial grade, Reimbold \& Strick, Germany).

Additionally, two types of composites were elaborated-one containing aluminosilica fibers Rockseal RS440-Roxul 1000 (Lapinus Fibers, The Netherlands) and the other containing 1F1417 Kevlar fibers (DuPont, France). Different composites were prepared containing 5, 10 and $15 \mathrm{phr}$ of each type of strengthening fibers.

Composite mixes were prepared using a Brabender (Germany) Plasticorder internal micro-mixer, operating with rotors speed of $20 \mathrm{rpm}$ during incorporation of the components and $60 \mathrm{rpm}$ during their homogenization (30 $\mathrm{min})$. Sheeting of mixes and orientation of fibers in silicone matrix were made on a David Bridge (UK) two-roll mill at $40^{\circ} \mathrm{C}$.

The crosslinking process of composites containing Kevlar fibers demanded parallel using of two agents beside dichlorobenzoyl peroxide, dicumyl peroxide were used.

In this paper investigated materials were described as: REF-composite containing additives of silica, fluxing agent and wollastonite; LAP-composites containing aluminosilicate fibers, additionally; KEV—composites containing Kevlar fibers, additionally.

Mechanical properties ( $\mathrm{SE}_{100}, \mathrm{SE}_{200}$ - stress at 100 and $200 \%$ elongation respectively, TS - tensile strength, and $\mathrm{E}_{\mathrm{b}}$ - elongation at break) of vulcanized composites were investigated using Zwick 1435 instrument.

Microstructures of broken samples were observed using Hitachi S-3000N scanning electron microscope under $100 \mathrm{~Pa}$ vacuum with BSE analysis mode.

Ceramization tests were performed by heating with a relatively slow temperature increase from $20^{\circ} \mathrm{C}$ up to $1000^{\circ} \mathrm{C}$ and 20 minutes of soaking time at maximum temperature.

Ceramized samples were subjected to compression tests using a Zwick Roell Z2.5 instrument (Germany). The maximum force required to destroy a composite sample was detected. The sample was in shape of disc 15 $\mathrm{mm}$ in diameter and $10 \mathrm{~mm}$ in height. Strength test was performed as compression probe when stress was applied perpendicularly to sample diameter. The mechanical strength of the ceramized materials was calculated as an average value of 5 probes.

Microstructures of ceramized samples were examined by scanning electron microscopy using Nova Nano SEM 200 (FEI, UK) apparatus.

The pore size distribution of ceramized materials was analyzed using mercury porosimetre Poremaster 60 (Quantachrome, USA).

\section{Results and Discussion}

Mechanical properties of the silicone composites tested paralelly $(\|)$ or perpendicularly $(\perp)$ to fibers arrangement in composites are presented in Table $\mathbf{1}$.

It is worth to notice that REF material containing mainly wollastonite as mineral filler has the average level of mechanical parameters. Incorporation of aluminosilicate long fibres significantly increased tensile strength of composites in the 5 - 10 phr range of incorporated fibers amount. This strengthening effect was much distinct when it was measured in direction parallel to loading direction. Composites containing Kevlar fibers were much more stiffer. Strengthening effect was observed in the case of fibers addition on $5 \mathrm{phr}$ level but elongation at break $\left(E_{b}\right)$ was shorter. Addition of higher amounts of Kevlar fibers (10 and $15 \mathrm{phr}$ ) did not lead to tensile strength increase and stiffness of the samples increased significantly.

Figures 1-3 illustrates broken composite surfaces after tensile strength measurements. In the Figure 1 elongated grains are wollastonite particles. They are rather brittle and their influence to tensile strength is not so big. Figure 2 shows the LAP composite fracture surface. Clearly visible are aluminosilicate fibers broken perpendicularly to fiber diameter. It suggests that adhesion of fibers to matrix is strong enough to improve composite

Table 1. Mechanical properties of investigated composites.

\begin{tabular}{|c|c|c|c|c|}
\hline & $\mathrm{SE}_{100}[\mathrm{MPa}]$ & $\mathrm{SE}_{200}[\mathrm{MPa}]$ & $\mathrm{TS}$ [MPa] & $\mathrm{E}_{\mathrm{b}}[\%]$ \\
\hline REF & 2.0 & 3.1 & 3.9 & 255 \\
\hline LAP $5 \perp$ & 2.0 & 3.2 & 4.2 & 265 \\
\hline LAP 5 || & 2.6 & 3.8 & 5.4 & 285 \\
\hline LAP $10 \perp$ & 2.1 & 3.2 & 4.5 & 270 \\
\hline LAP 10|| & 2.7 & 3.8 & 5.7 & 295 \\
\hline LAP $15 \perp$ & 2.1 & 3.2 & 4.2 & 270 \\
\hline LAP 15|| & 2.6 & 3.7 & 4.0 & 220 \\
\hline $\mathrm{KEV} 5 \perp$ & 2.8 & 4.1 & 4.7 & 240 \\
\hline KEV 5 || & 3.7 & 4.9 & 5.1 & 210 \\
\hline $\mathrm{KEV} 10 \perp$ & 3.4 & - & 3.4 & 115 \\
\hline KEV 10|| & - & - & 3.2 & 30 \\
\hline $\mathrm{KEV} 15 \perp$ & - & - & 3.6 & 85 \\
\hline KEV 15|| & - & - & 4.7 & 35 \\
\hline
\end{tabular}




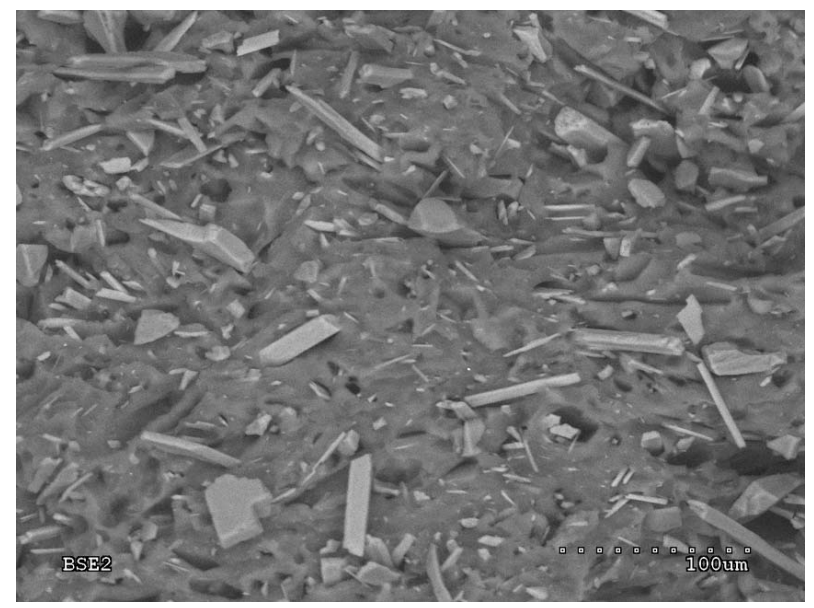

Figure 1. SEM micrograph of a typical area of REF composite after the strength test.

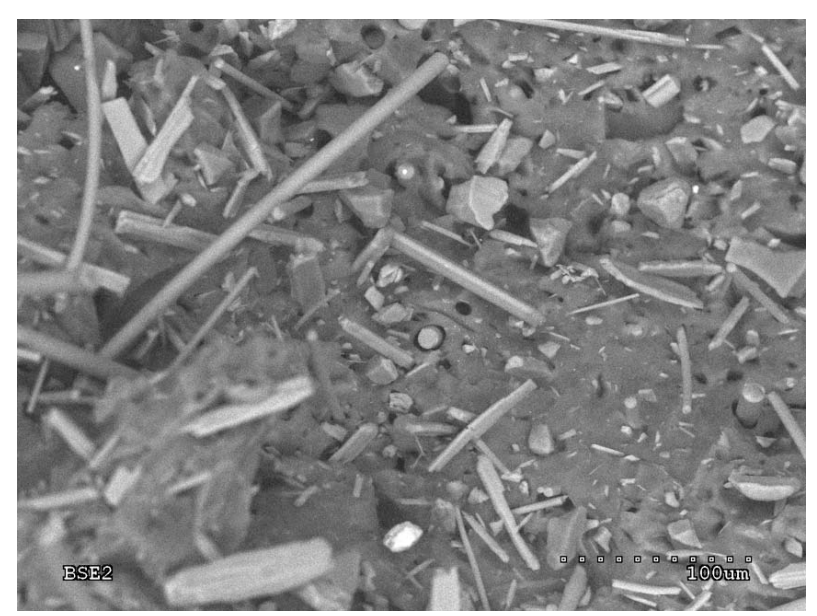

Figure 2. SEM micrograph of a typical area of LAP composite after the strength test.

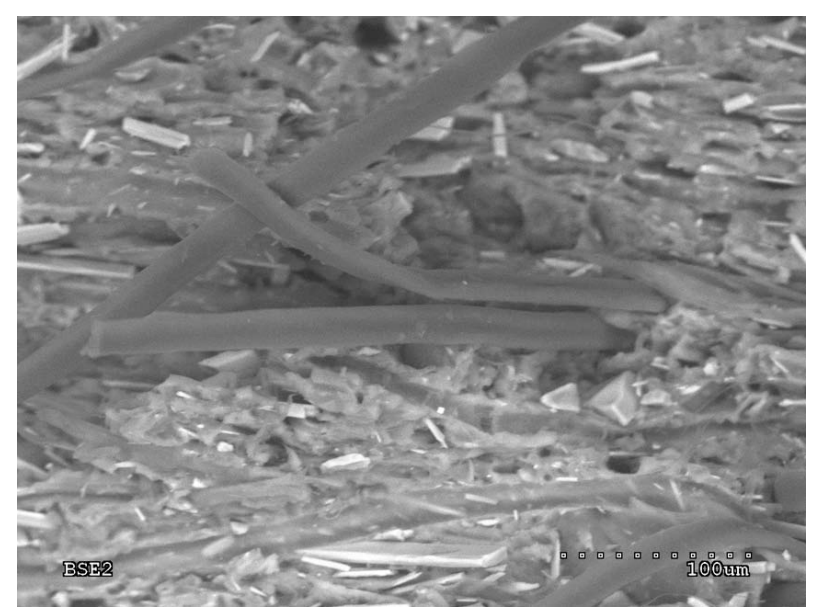

Figure 3. SEM micrograph of a typical area of KEV composite after the strength test.

strength. Moderate increase of the tensile strength in the case of composites containing aluminosilicate fibers (5 and $10 \mathrm{phr}$ ) arranged perpendicularly to tensile force was probably caused by easier fracture of long brittle fibers during loading not parallel to fiber axis. This effect was not observed in the case of composite containing $15 \mathrm{phr}$ of aluminosilicate fibers. Its tensile strength measured for both fiber orientations was similar and bigger about $10 \%$ only than this measured for composite without fibers. This fact indicated the limit of effective acting of aluminosilicate long fibers addition.

The analyze of broken surface of composites containing the Kevlar fibers showed in all cases the presence of fibers distinctly pulled apart of the material. In Figure 3 these fibers are clearly visible as elongated gray objects. The poor adhesion of Kevlar fibers to silicone rubber and the rest of composite components limited the strengthening effect only to composition containing 5 phr of fibers. Addition of higher amounts of Kevlar fibers (10 and 15 phr) caused significant increase of composite stiffness. This effect is very strong and could not be profitable cable for industry demands.

Microstructures of ceramized samples are presented in Figures 4-6. The analysis of these images indicates that REF composite after ceramization is composed of big wollastonite grains and small silica ones. As it was determined by mercury porosimetry the total porosity of this composite was about $61.6 \%$. The total porosity of LAP composites was changed between 59.5 and $62.6 \%$ depending on fibers content (5 - $15 \mathrm{phr}$ ).

The total porosity of KEV composites was changed between 60.7 and $64.5 \%$ depending on fibers content (5 $15 \mathrm{phr})$.

The main difference between LAP and KEV composites microstructures after ceramization was the fact that aluminosilicate fibers after firing still were present in the

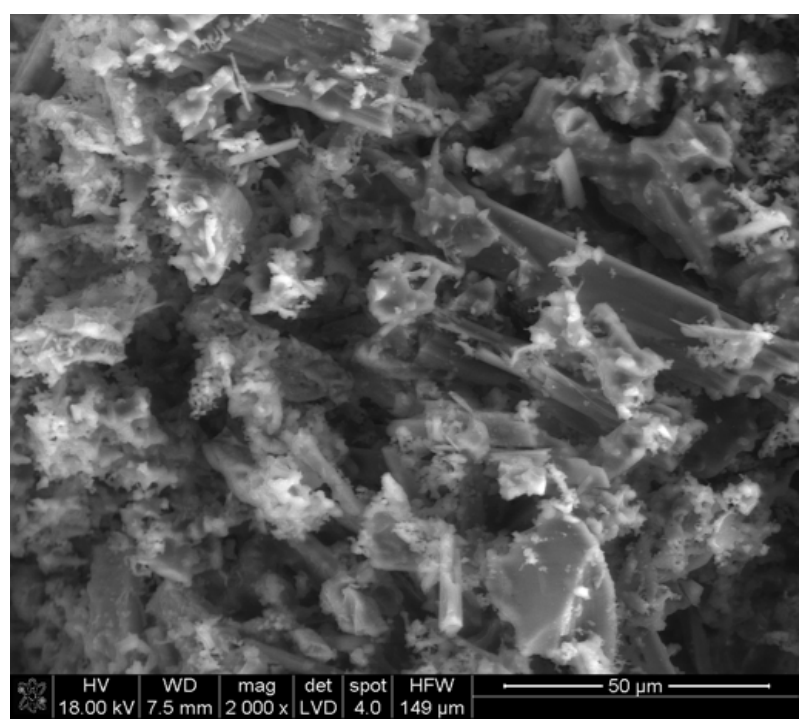

Figure 4. SEM micrograph of a typical area of ceramized REF composite sample. 


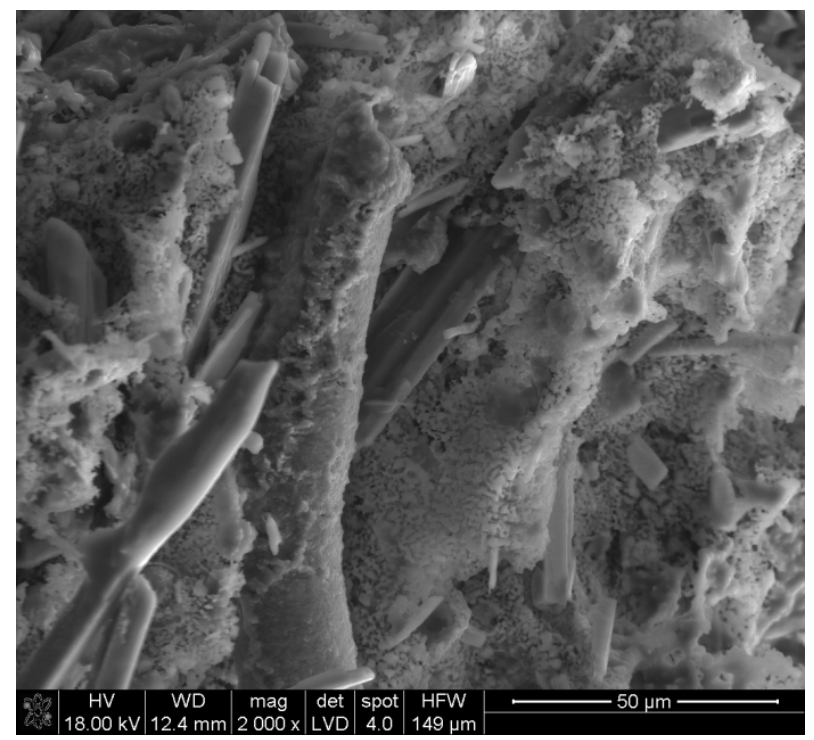

Figure 5. SEM micrograph of a typical area of ceramized LAP composite sample.

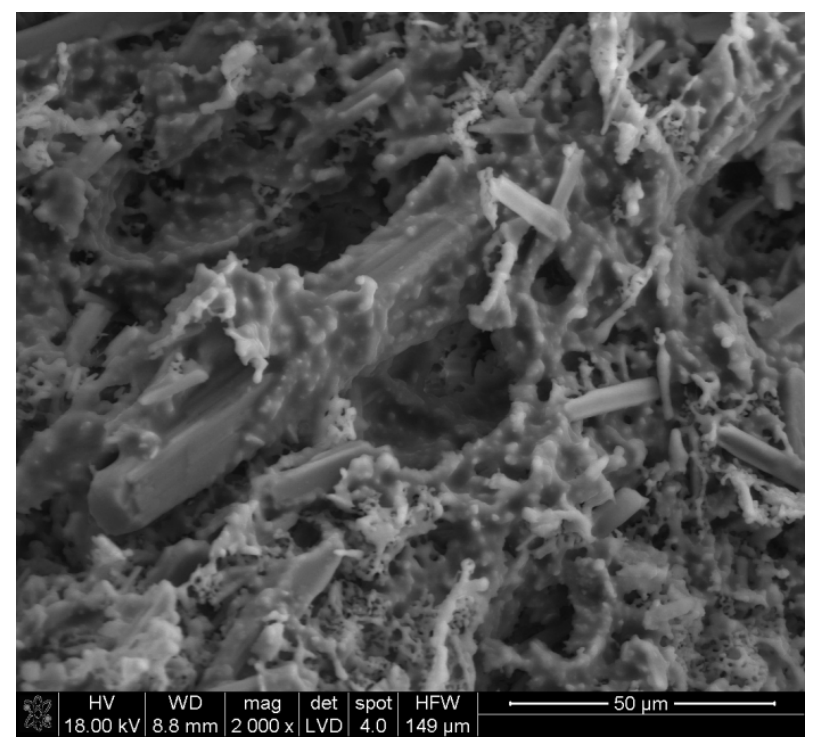

Figure 6. SEM micrograph of a typical area of ceramized KEV composite sample.

composite microstructure (see Figure 5). Kevlar fibers after firing at $1000^{\circ} \mathrm{C}$ disappeared (see Figure 6).

However, investigation of ceramized composites samples did not show significant differences between the total amount of pores volume and their size distribution among all types of composites (see Figures 7 and 8). Additionally, no significant differences in porosity were detected between samples containing 5, 10 or $15 \mathrm{phr}$ of long fibers. It means that microstructures of ceramized bodies were very similar. Ceramized bodies showed pores bigger than 1 micrometer. It means that fluxing agent acted very effectively and it joined together wollastonite particles and ultrafine silica particles produced

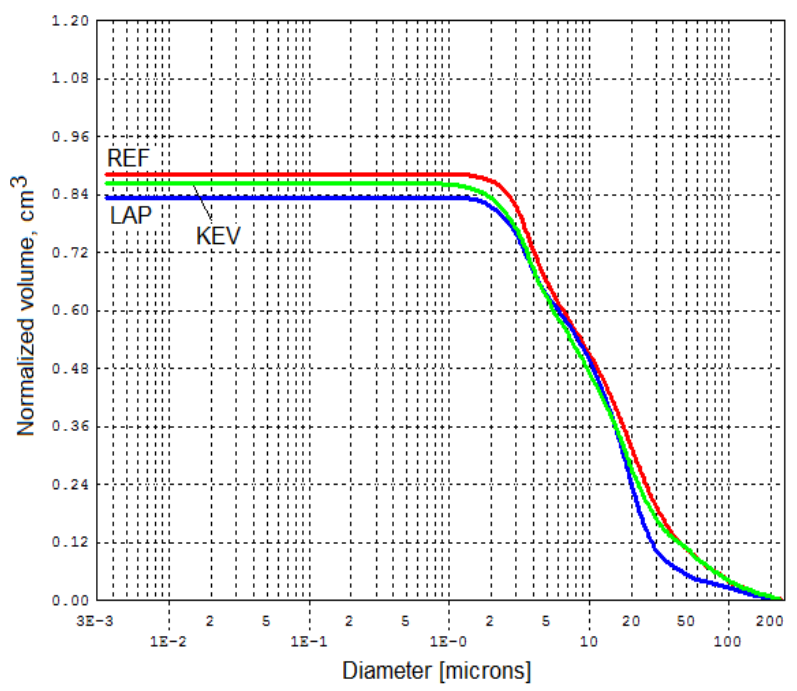

Figure 7. The cumulative curves of pore size distribution of ceramized reference material (REF) and containing 5 phr of mineral (LAP) or Kevlar (KEV) fibers.

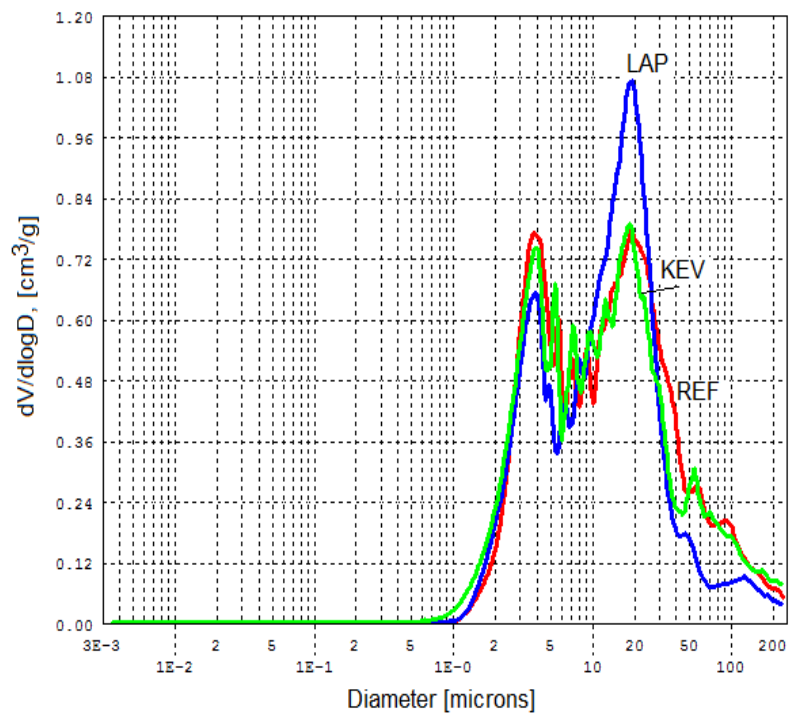

Figure 8. The differential curves of pore size distribution of ceramized reference material (REF) and containing 5 phr of mineral (LAP) or Kevlar (KEV) fibers.

as silicone rubber decomposition effect. Two fractions of bigger pores ( $\sim 5$ micrometers and $\sim 20$ micrometers) were created as an effect of agglomeration.

The presence of long fibers was not so important for this process. The aluminosilicate fibers survived the ceramization process and they stayed present in the ceramized bodies. The Kevlar fibers disappeared during firing but it has no significant influence for the microstructure of ceramized bodies, most probably due to relatively low viscosity of mixture of fluxing agent and ceramization products.

Figure 9 summarized strength of ceramized bodies 


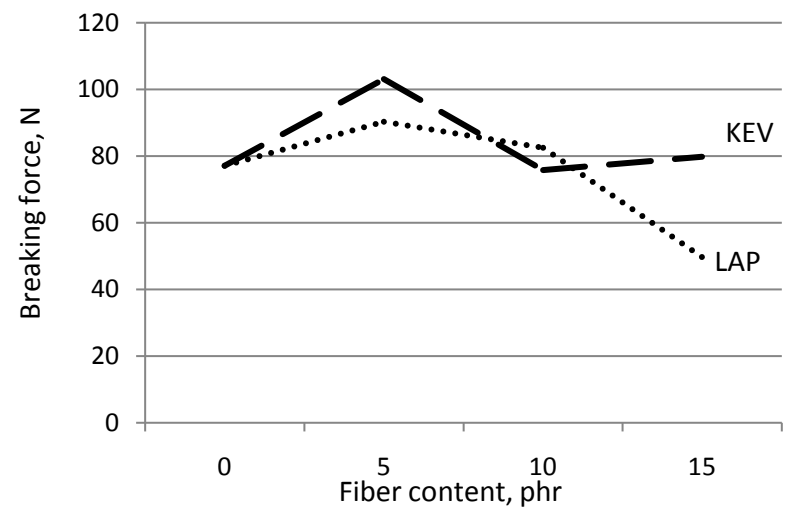

Figure 9. Plots of breaking force dependence vs. fibers content for mineral (LAP) and Kevlar (KEV) fibers. Samples were ceramized at $1000^{\circ} \mathrm{C}$.

investigations. Differences observed between elaborated samples were not significant. One can observe a slight increase of strength for composites containing 5 phr additions of both types of fibers. Such results were probably the effect of microstructure uniformization at high temperatures due to flowing of the fluxing agent.

\section{Summary}

Performed experiment confirms the possibility of reinforcing of silicone rubber-basing composites containing wollastonite particles with addition of long fibers.

The performance of specially oriented microstructures was successful and it was established that addition of small (5 - 10 phr) amounts of aluminosilicate fibers significantly increased composite tensile strength.

The Kevlar fibers have no good adhesion to the others material compounds and only the minimal used level of fibers gave property improvement.

All investigated materials showed good properties after firing. Ceramized bodies were tight, uniform and strong enough to be used in fire-protecting application.

Performed test recommended composites containing aluminosilicate fibers as more perspective for mentioned application.

\section{Acknowledgements}

The work was financially supported by the European Union within a framework of National Coherence Strategy under Innovative Economy Operating Programme (grant no. POIG.01.03.01-00-067/08) and by the Polish State Ministry for Science and High Education (AGH 11.11.160.364).

\section{REFERENCES}

[1] S. Hamdani, C. Longuet, D. Perrin, J.-M. Lopez-Cuesta and F. Ganachaud, "Flame Retardancy of Silicone-Based
Materials,” Polymer Degradation and Stability, Vol. 94, 2009, pp. 465-495.

http://dx.doi.org/10.1016/j.polymdegradstab.2008.11.019

[2] A. B. Morgan, L. L. Chu and J. D. Harris, “A Flammability Performance Comparsion between Synthetic and Natural Clays in Polystyrene Nanocomposites," Fire and Materials, Vol. 29, 2005, pp. 213-229. http://dx.doi.org/10.1002/fam.881

[3] J. Mansouri, R. P. Burford, Y. B. Cheng and L. Hanu, "Formation of Strong Ceramified Ash from SiliconeBased Composites," Journal of Materials Science, Vol. 40, 2005, pp. 5741-5749. http://dx.doi.org/10.1007/s10853-005-1427-8

[4] J. Mansouri, R. P. Burford and Y. B. Cheng, "Pyrolysis Behaviour of Silicone-Based Ceramifying Composites," Materials Science and Engineering A, Vol. 425, 2006, pp. 7-14. http://dx.doi.org/10.1016/j.msea.2006.03.047

[5] L. G. Hanu, G. P. Simon and Y. B. Cheng, "Preferential Orientation of Muscovite in Ceramifiable Silicone Composites," Materials Science and Engineering A, Vol. 398, 2005, pp. 180-187.

http://dx.doi.org/10.1016/j.msea.2005.03.022

[6] Y. Xiong, Q. Shen, F. Chen, G. Luo, K. Yu and L. Zhang, "High Strength Retention and Dimensional Stability of Silicone/Alumina Composite Panel under Fire,” Fire and Materials, Vol. 36, 2012, pp. 254-263. http://dx.doi.org/10.1002/fam.1107

[7] K. Hayashida, S. Tsuge and H. Othani, "Flame Retardant Mechanizm of Polydimethylsiloxane Material Containing Compound Studied by Analytical Pyrolysis Techniques and Alkaline Hydrolysis Gas Chromatography,” Polymer, Vol. 44, 2003, pp. 5611-5616. http://dx.doi.org/10.1016/S0032-3861(03)00622-0

[8] S. Hamdani, C. Longuet, J.-M. Lopez-Cuesta and F. Ganachaud, "Calcium and Aluminium-Based Fillers as Flame-Retardant Additives in Silicone Matrices. I. Blend Preparation and Thermal Properties,” Polymer Degradation and Stability, Vol. 95, 2010, pp. 1911-1919.

http://dx.doi.org/10.1016/j.polymdegradstab.2010.04.013

[9] Z. Pedzich and D. M. Bielinski, "Microstructure of Silicone Composites after Ceramization,” Composites, Vol. 10, 2010, pp. 249-254.

[10] Z. Pedzich, D. M. Bielinski, J. Dul, M. Zarzecka-Napierala, "Optimisation of the Ceramic Phase for Ceramizable Silicone Rubber Based Composites,” IOP Conference Series: Materials Science and Engineering, Vol. 18, 2011, Article ID: 202027.

[11] Z. Pędzich, A. Bukanska, D. M. Bieliński, R. Anyszka, J. Dul and G. Parys, "Microstructure Evolution of Silicone Rubber-Based Composites during Ceramization at Different Conditions," International Journal of Advanced Materials Manufacturing \& Characterization, Vol. 1, No. 1, 2012, pp. 29-35.

[12] J. Dul, G. Parys, Z. Pędzich, D. M. Bieliński and R. Anyszka, "Mechanical Properties of Silicone-Based Composites Destined for Wire Covers,” International Journal of Advanced Materials Manufacturing \& Characterization, Vol. 1, No. 1, 2012, pp. 29-35. 
[13] G. Marosi, A. Márton, P. Anna, G. Bertalan, B. Marosföi and A. Szép, "Ceramic Precursor in Flame Retardant Systems,” Polymer Degradation and Stability, Vol. 77, 2002, pp. 259-265.

http://dx.doi.org/10.1016/S0141-3910(02)00057-5

[14] J. Mansouri, C. A. Wood, K. Roberts, Y. B. Cheng and R. P. Burford, "Investigation of the Ceramifying Process of Modified Silicone-Silicate Compositions," Journal of Materials Science, Vol. 42, 2007, pp. 6046-6055. http://dx.doi.org/10.1007/s10853-006-1163-8

[15] L. G. Hanu, G. P. Simon, J. Mansouri, R. P. Burford and Y. B. Cheng, "Development of Polymer-Ceramic Composites for Improved Fire Resistance,” Journal of Materials Processing Technology, Vol. 153-154, 2004, pp. 401-407. http://dx.doi.org/10.1016/j.jmatprotec.2004.04.104

[16] D. M. Bieliński, R. Anyszka, Z. Pędzich and J. Dul, “Ceramizable Silicone Rubber-Based Composites,” International Journal of Advanced Materials Manufacturing \& Characterization, Vol. 1, No. 1, 2012, pp. 17-22.

[17] L. G. Hanu, G. P. Simon and Y. B. Cheng, "Thermal Stability and Flammability of Silicone Polymer Composites,” Polymer Degradation and Stability, Vol. 91, 2006, pp. $1373-1379$.

http://dx.doi.org/10.1016/j.polymdegradstab.2005.07.021

[18] Z. Pędzich, A. Bukanska, D. M. Bieliński, R. Anyszka, J. Dul and G. Parys, "Microstructure Evolution of Silicone Rubber-Based Composites during Ceramization at Different Conditions," International Journal of Advanced Materials Manufacturing \& Characterization, Vol. 1, No. 1, 2012, pp. 29-35.

[19] "Processable Silicone Composite Materials Having High Temperature Resistance,” US Patent 5552466, 03.08.1996.

[20] D. Ariagno, P. Barruel and A. Viale, "Heat-Vulcanisable Organopolysiloxanes, Intended for Coating of Electrical Cables,” European Patent 0,467,800, 1992.

[21] "Flammwidrige Zusammensetzung zur Herstellung von Elektrischen Kabeln mit Isolations-und/oder Funktionserhalt,” EP 0708455 A1, 24.04.1996.

[22] "A Fire Performance Material and Cable including the Material,” WO Patent 2010/097705 A1, 02.09.2010.

[23] P. Branlard, C. George and C. Leuci, "Polyorganosiloxane Compositions Vulcanisable by Hot Process Useful in Particular for Making Electric Wires or Cables,” European Patent 1,238,007, 2003. 